\title{
PERCEPTION OF EASIENES IN USING FINTECH IN MSMES
}

Bambang Sugiharto ${ }^{1 *}$, Sri Mulyati ${ }^{2}$, Aprillia Verra Puspita ${ }^{3}$

$1^{*}, 2,3$ Sekolah Tinggi Ilmu Ekonomi Sutaatmadja, Subang, Indonesia ‘bambangsugihart@gmail.com

INFO ARTIKEL

Histori Artikel :

Tgl. Masuk : 01 September 2020

Tgl. Diterima : 29 September 2020

Tersedia Online : 29 September 2020

Keywords:

Fintech, Usaha Mikro Kecil Menengah (UMKM)
ABSTRAK

Penelitian ini bertujuan untuk mengetahui persepsi
kemudahan penggunaan fintech dalam pembiayaan
UMKM. metode penelitian yang digunakan adalah
kuantitatif dengan menggunakan Sumber data primer yang
diperoleh melalui kuesioner yang dibagikan dan diisi oleh
responden. Teknik pengambilan sampling yang digunakan
dalam penelitian ini adalah purposive sampling. Populasi
dalam penelitian ini adalah UMKM yang ada di kabupaten
Subang Hasil penelitian menunjukkan bahwa adanya
hubungan antara fintech dengan pembiayaan UMKM,
dimana para pelaku UMKM mengalami peningkatan dalam
penjualannya karena adanya fintech, fintech membuat
kemudahan dalam pembiayaan.

UMKM semakin meningkat maka akan memberikan dampak yang baik dalam penyerapan tenaga kerja dan pertumbuhan ekonomi di Indonesia.

Sedangkan menurut ukurannya, tabel berikut merupakan data perkembangan Usaha Mikro, Kecil dan Menengah (UMKM) :

rakyatnya. Salah satu roda penggerak perekonomian negara adalah UMKM. Pada Tahun 2016 UMKM di Indonesia mencapai 61.651.177 unit, yang memberikan sumbangan PDB sebesar $59 \%$ dan membuat lapangan pekerjaan sebesar $97 \%$ tenaga kerja.

Berikut ini adalah perkembangan data Usaha Mikro, Kecil dan Menengah (UMKM) :

\section{Tabel 1.1 Perkembangan Data Usaha}

Mikro, Kecil, dan Menengah (UMKM)

Sumber : www.depkop.go.id

Berdasarkan tabel 1.1 diatas dapat dilihat bahwa perkembangan UMKM di Indonesia terus bertambah dari 59.262.772 unit pada tahun 2014 hingga 62.922.617 unit pada tahun 2017. Jika

\begin{tabular}{|c|l|l|l|l|l|}
\hline \multirow{2}{*}{ Tahun } & UMKM & \multicolumn{2}{|c|}{ PDB } & \multicolumn{2}{c|}{ Tenaga Kerja } \\
\cline { 2 - 6 } & Jumlah & \multicolumn{1}{|c|}{ Jumlah } & Persentase & Jumlah & $\begin{array}{c}\text { Pers } \\
\text { entas } \\
\text { e }\end{array}$ \\
\hline 2014 & $\begin{array}{l}57.895 .721 \\
\text { unit }\end{array}$ & $\begin{array}{l}\text { Rp. 5.440.007,9 } \\
\text { Milyar }\end{array}$ & $60,34 \%$ & $\begin{array}{l}114.144 .082 \\
\text { orang }\end{array}$ & $\begin{array}{c}96,99 \\
\%\end{array}$ \\
\hline 2015 & $\begin{array}{l}59.262 .772 \\
\text { unit }\end{array}$ & $\begin{array}{l}\text { Rp. } 6.228 .285,0 \\
\text { Milyar }\end{array}$ & $61,41 \%$ & $\begin{array}{l}123.229 .386 \\
\text { orang }\end{array}$ & $\begin{array}{c}96,71 \\
\%\end{array}$ \\
\hline 2016 & $\begin{array}{l}61.651 .177 \\
\text { unit }\end{array}$ & $\begin{array}{l}\text { Rp. } 7.009 .283,0 \\
\text { Milyar }\end{array}$ & $59,84 \%$ & $\begin{array}{l}112.828 .610 \\
\text { orang }\end{array}$ & $\begin{array}{c}97,04 \\
\%\end{array}$ \\
\hline 2017 & $\begin{array}{l}62.922 .61 \\
7 \text { unit }\end{array}$ & $\begin{array}{l}\text { Rp. } \\
7.704 .635,9 \\
\text { Milyar }\end{array}$ & $60,00 \%$ & $\begin{array}{l}116.673 .41 \\
6 \text { orang }\end{array}$ & $\begin{array}{l}97,0 \\
2 \%\end{array}$ \\
\hline
\end{tabular}

\section{Tabel 1.2 Rincian Data Perkembangan Usaha Mikro, Kecil, dan Menengah (UMKM) Di Indonesia}




\begin{tabular}{|l|c|c|c|c|}
\hline \multirow{2}{*}{ UMKM } & \multicolumn{4}{|c|}{ Tahun } \\
\cline { 2 - 5 } & $\mathbf{2 0 1 4}$ & $\mathbf{2 0 1 5}$ & $\mathbf{2 0 1 6}$ & $\mathbf{2 0 1 7}$ \\
\hline $\begin{array}{l}\text { Usaha } \\
\text { Mikro }\end{array}$ & 57.189 .393 & 58.521 .987 & 60.863 .578 & 62.106 .900 \\
\hline $\begin{array}{l}\text { Usaha } \\
\text { Kecil }\end{array}$ & 654.222 & 681.522 & 731.047 & 757.090 \\
\hline $\begin{array}{l}\text { Usaha } \\
\text { Menengah }\end{array}$ & 52.106 & 59.263 & 56.551 & 58.627 \\
\hline \multicolumn{1}{|c|}{ Total } & $\mathbf{5 7 . 8 9 5 . 7 2 1}$ & $\mathbf{5 9 . 2 6 2 . 7 7 2 6 1 . 6 5 1 . 1 7 7}$ & $\mathbf{6 2 . 9 2 2 . 6 1 7}$ \\
\hline
\end{tabular}

Sumber : www.depkop.go.id

Permasalahan UMKM yang
seringkali timbul adalah dalam
pemenuhan permodalan, dimana untuk
memenuhi kekurangan permodalan
diperlukan akses ke lembaga keuangan, hal inilah yang seringkali menjadi kendala bagi UMKM. Sehingga ketika sumber pembiayaan itu kecil maka akan menimbulkan masalah keuangan. Kendala dalam hal keuangan akan membuat suatu UMKM kurang mengalami perkembangan yang signifikan dalam hal membangun dan memperluas bisnis (Abor dan Quartey, 2010).

Dewasa ini perkembangan teknologi maju dengan pesat, hal ini juga berimbas pada perekonomian dimana dengan kemajuan teknologi tersebut maka hadir cara bertransaksi secara daring baik transaksi pembayaran maupun pembiayaan atau yang disebut dengan Financial Technology (Fintech) sehingga membuat transaksi lebih efisien. Menurut Bank Indonesia Fintech adalah hasil gabungan antara jasa keuangan dengan teknologi yang akhirnya mengubah model bisnis dari konvensional menjadi moderat, yang awalnya dalam membayar harus bertatap-muka dan membawa sejumlah uang kas, kini dapat melakukan transaksi jarak jauh dengan melakukan pembayaran yang dapat dilakukan dalam hitungan detik saja. Fintech dalam Bank Indonesia diatur dalam Peraturan Bank Indonesia No. 18/40/PBI/2016 tentang Penyelenggaraan Pemrosesan Transaksi Pembayaran. Sehingga Fintech itu legal untuk digunakan.
Perkembangan Fintech saat ini sangat berpengaruh pada UMKM dimana ketika UMKM membutuhkan pembiayaan, maka Fintech dapat membantu dalam pembiayaannya. Sudah jelas bahwa UMKM menjadi lebih produktif ketika pembiayaan dalam sebuah usaha tersebut lancar. Peer to Peer Lending (P2P Lending) merupakan sebuah inovasi yang ada dalam fintech. P2P diluncurkan tahun 2005 yang digunakan untuk praktik penjam meminjam tanpa melalui perantara keuangan tradisional seperti bank (World Economic Forum, 2015). System Peer to Peer yaitu investor akan bertemu dengan peminjam untuk membuat kesepakatan yang dilakukan secara digital, maka peminjam akan mendapatkan dana secara cepat, mudah, dan efisien (Embun, 2018). P2P ini lebih digunakan oleh start-up (wirausaha baru) dalam memperoleh sumber pembiayaan dalam usahanya. Fintech sangat digemari oleh masyarakat sehingga banyak perusahaan start-up yang berlomba-lomba dalam mengembangkan Fintech. Fintech membantu UMKM yang membutuhkan pembiayaan untuk usaha bagi mereka yang tidak bisa mengakses perbankan. UMKM yang ingin mengembangkan usahanya dapat melakukan pinjaman kepada Fintech. Walaupun Fintech tergolong baru dalam dunia perekonomian namun pengguna Fintech sudah banyak di Indonesia, karena Fintech hadir dengan beberapa kemudahan.

Seperti yang dikatakan Endang Srikarti Handayani, SH, MHUM sebagai Anggota Komisi VI DPR yaitu "Program pembiayaan Usaha Mikro, Kecil, dan Menengah (UMKM) dari Lembaga Pengelola Dana Bergulir (LPDB) yang dinilai berbelit-belit, seharusnya para pelaku UMKM tidak dipersulit dalam mengakses pembiayaan dana, bantuan permodalan bagi UMKM sangatlah penting sebagai upaya untuk mempertahankan 
keberlanjutan usaha mereka, apalagi tingkat persaingan dinilai sudah semakin ketat di dalam era globalisasi seperti yang terjadi saat ini karena jika UMKM mengalami perkembangan maka akan meningkatkan pertumbuhan ekonomi serta mengurangi angka ketimpangan nasional". Menurut Deputi Komisioner OJK Sukarela Batunanggar, salah satu yang paling terasa manfaatnya adalah para pelaku Usaha Usaha Mikro Kecil Menengah (UMKM). Menurutnya, banyak UMKM yang merasakan dampak dari adanya P2P lending ini, khususnya dalam mendapatkan pinjaman modal. Sebelum adanya P2P lending ini, UMKM kesulitan mendapatkan modal. Karena usahanya yang belum terlalu besar membuat pelaku UMKM ini tidak bankable. OJK mencatat penyaluran kredit kepada Usaha Mikro, Kecil dan Menengah (UMKM) melalui Peer to Peer (P2P) Lending mencapai Rp25,9 triliun per Januari 2019.

Berdasarkan hal tersebut, penelitian ini bertujuan untuk melihat persepsi kemudahan penggunaan fintech dalam pembiayaan UMKM, dengan menggunakan teori Technology Acceptance Model (TAM) (Davis, Bagozzi \& Warshaw; 1989). Tujuannya untuk menjelaskan dan memprediksikan penerimaan pemakai terhadap suatu teknologi. Dalam hal ini, yang dimaksud adalah teknologi fintech. Perspektif kemudahan penggunaan dapat meyakinkan pengguna bahwasanya teknologi informasi yang akan diaplikasikan adalah suatu hal yang mudah dan bukan merupakan beban bagi mereka. Davis (1989) dalam bukunya juga menyatakan bahwa perspektif kemudahan pengaplikasian (perceived ease of use) merupakan sebuah tingkatan dimana seseorang percaya bahwasanya penggunaan sistem tertentu, mampu mengurangi usaha seseorang dalam mengerjakan sesuatu.

\section{KERANGKA TEORITIS DAN PENGEMBANGAN HIPOTESIS Theory Technology Acceptance Model} Menurut Davis, Bagozzi \& Warshaw (1989) Technology Acceptance Model (TAM) adalah teori yang menjelaskan tentang penerimaan pengguna terhadap system informasi, Technology Acceptance Model (TAM) diadaptasi dari Theory of Reasoned Action (TRA). TAM dirancang untuk penerimaan pengguna sistem informasi dengan tujuan untuk menjelaskan manfaat dan kemudahan menggunakan sistem informasi (Farn dkk,2006). Technology Acceptance Model adalah model terbaik untuk membantu dalam memahami penggunaan teknologi informasi (Taylor \& Todd, 1995).

Ada 2 (dua) persepsi dalam Technology Acceptance Model (TAM) yaitu: (1) persepsi kegunaan (perceived usefulness) yang mengacu pada "sejauh mana seseorang percaya bahwa menggunakan sistem tertentu akan meningkatkan kinerja pekerjaan." dan, (2) persepsi kemudahan penggunaan (perceived ease of use) mengacu pada "tingkat kepercayaan seseorang bahwa penggunaan sistem tertentu akan mengurangi atau membebaskan dari usaha fisik dan mental". (Davis dkk,1989). Tujuan dengan adanya TAM untuk menyediakan penjelasan tentang faktorfaktor penentu penerimaan teknologi yang bersifat umum, mampu menjelaskan perilaku pengguna di berbagai teknologi komputasi (Davis dkk,1989).

\section{Usaha Mikro, Kecil, dan Menengah (UMKM)}

Usaha Mikro, Kecil, dan Menengah atau disingkat UMKM adalah usaha ekonomi produktif yang berdiri sendiri, yang dilakukan oleh orang perorangan atau badan usaha yang bukan merupakan anak perusahaan atau bukan cabang 
perusahaan lain serta memiliki jumlah kekayaan yang bervariasi sesuai dengan golongannya yang diatur dalam UU No 20 Tahun 2008 tentang Usaha Mikro, Kecil, dan Menengah (UMKM),

\section{Pembiayaan}

Menurut Undang-Undang Nomor 20 Tahun 2008 pasal 1 angka 11 tentang Usaha Mikro, Kecil, dan Menengah (UMKM) pembiayaan adalah penyediaan dana oleh Pemerintah, Pemerintah Daerah, Dunia Usaha, dan masyarakat dengan melalui bank, koperasi, dan lembaga keuangan bukan bank, untuk mengembangkan dan memperkuat permodalan Usaha Mikro, Kecil, dan Menengah. Indikator pembiayaan menurut Hadjimanolis (2000) dalam Rizkia dan Badan Pengkajian dan Pengembangan Kebijakan Perdagangan: meliputi : (1)

Penggunaan pembiayaan;

Peningkatan omset penjualan; (3) Pertumbuhan pelanggan; (4) Laba usaha.

\section{Financial Technology (Fintech)}

Menurut Bank Indonesia Financial Technology (Fintech) adalah penggunaan teknologi dalam sistem keuangan yang menghasilkan produk, layanan, teknologi, dan/atau model bisnis baru serta dapat berdampak pada stabilitas moneter, stabilitas sistem keuangan, dan/atau efisiensi, kelancaran, keamanan, dan keandalan sistem pembayaran. Fintech muncul karena perkembangan. Di dalam data Otoritas Jasa Keuangan saat ini jumlah penyelenggara fintech terdaftar dan berizin adalah sebanyak 113 perusahaan per 31 Mei 2019.

Industri Fintech saat ini paling digemari oleh masyarakat Indonesia sehingga merupakan sektor yang paling berkembang. pemerintah mengharapkan sektor inilah yang mampu mendorong peningkatan jumlah masyarakat yang memiliki akses kepada layanan keuangan (Muzdalifah, 2018). Fintech dikategorikan menjadi 4 (empat) yaitu: (1) Crowdfunding dan Peer to Peer Lending (P2P); (2) Payment, Clearing, Settlement; (3) Market Aggregator; (4) Manajemen Risiko dan Investasi

\section{Persepsi Kemudahan Penggunaan}

Persepsi kemudahan penggunaan adalah suatu anggapan individu dimana jika mereka menggunakan sistem tertentu maka akan bebas dari usaha (Harlan,2015). Definisi tersebut didukung pula oleh Wibowo (2006) yaitu menjelaskan bahwa persepsi tentang kemudahan penggunaan sebuah teknologi didefinisikan dengan suatu ukuran yang dimana membuat seseorang percaya bahwa dengan adanya teknologi maka akan menjadi lebih mudah dipahami dan digunakan. Menurut Davis (2000) dan Ahmad (2013) dalam Aliyah indikator persepsi kemudahan penggunaan menjadi berikut: (1). Teknologi informasi mudah dimengerti; (2) Sistem teknologi informasi mudah digunakan; Keyakinan akan kemanfaatan.

\section{Persepsi Kemudahan Penggunaan Fintech Dalam Pembiayaan Umkm}

Dalam penelitian Wibowo (2016) Fintech dapat bekerja sama dengan industri keuangan yang memberi berbagai manfaat untuk masyarakat. Fintech yang berbasis Peer to Peer Lending (P2P) menjadi peluang baru dalam pengembangan usaha (Galloway, 2009). Menurut Financial Stability Board (FSB) inovasi yang berbentuk Financial Technology (Fintech) dalam perkembangan UMKM memberikan manfaat yaitu : (1) dengan adanya Fintech dalam memberikan layanan pembayaran yang lebih efisien membuat semakin besar efisiensi pemain baru dalam menggunakan layanan keuangan yang berpotensi memberikan keuntungan (2) Memberikan pembiayaan dalam bentuk kredit kepada masyarakat yang memiliki usaha sehingga meningkatkan sumber permodalan dalam pengembangan usaha 
(3) penggunaan Fintech semakin meningkat sehingga diperlukan mengelola risiko dengan tepat untuk meminimalisir risiko operasional dan keamanan

\section{Pengembangan Hipotesis}

Menurut Nur Arifah (2018) Financial technology merupakan inovasi yang dinilai dapat meningkatkan pangsa pasar UMKM sebagai langkah dalam mengatasi permasalahan terkait pembiayaan modal, penyunsunan laporan keuangan, pembayaran dan pemasaran, serta transaksi keuangan dan literasi keuangan lainnya Berdasarkan uraian diatas maka hipotesis yang di tarik adalah :

$\mathrm{H} 1$ : persepsi kemudahan penggunaan

fintech berpengaruh terhadap

pembiayaan umkm

\section{METODOLOGI PENELITIAN}

Penelitian ini menggunakan penelitian kuantitatif. Sumber data yang digunakan dalam penelitian ini adalah sumber primer yang diperoleh melalui kuesioner yang dibagikan dan diisi oleh responden yang berhubungan dengan penelitian yang dilakukan. Teknik sampling yang digunakan dalam penelitian ini adalah non probability sampling dengan teknik yang diambil yaitu purposive sampling. Populasi dalam penelitian ini adalah UMKM yang ada di kabupaten Subang

Roscoe (1975) dalam Uma Sakaran (1992) memberikan pedoman penentuan jumlah sampel sebaiknya ukuran sampel diantara 30 sampai denga 500 elemen. Dalam penelitian ini sampel yang di peroleh sebanyak 60 responden. Variabel dalam penelitian ini terdiri dari variabel independen yaitu kemudahan penggunaan fintech, sedangkan variabel dependennya adalah pembiayaan UMKM. Adapun pengertian dan pengukuran variabel dapat dilihat pada tabel berikut ini

\section{Tabel 3.1 Operasionalisasi Variabel}

\begin{tabular}{|c|c|c|c|}
\hline Variabel & Definisi Variabel & Indikator & Skala \\
\hline $\begin{array}{l}\text { Pembiayaan } \\
\text { UMKM (Y) }\end{array}$ & $\begin{array}{l}\text { Penyediaan dana oleh } \\
\text { Pemerintah, Pemerintah } \\
\text { Daerah, Dunia } \\
\text { dan masaha, } \\
\text { melalui bank, koperasi, } \\
\text { dan lembaga keuangan } \\
\text { bukan bank, untuk } \\
\text { mengembangkan } \\
\text { memperkuat dan } \\
\text { permodalan } \\
\text { Mikro, Kecil, } \\
\text { Menengah dan } \\
\text { (UU No. 20 Tahun 2008 } \\
\text { pasal 1 angka 11 tentang } \\
\text { UMKM) }\end{array}$ & $\begin{array}{ll}\text { a. } & \begin{array}{l}\text { Penggunaan } \\
\text { pembiayaan }\end{array} \\
\text { b. } & \text { Peningkatan } \\
& \text { omset } \\
& \text { penjualan } \\
\text { c. } & \text { Pertumbuhan } \\
& \text { pelanggan } \\
\text { d. } & \text { Laba usaha } \\
\text { (Hadjimanolis, } \\
\text { 2000) }\end{array}$ & Liker \\
\hline $\begin{array}{l}\text { Persepsi } \\
\text { Kemudahan } \\
\text { Penggunaan } \\
\text { Fintech }(\mathrm{X})\end{array}$ & $\begin{array}{|lr|}\text { merupakan } & \text { sebuah } \\
\text { tingkatan } & \text { dimana } \\
\text { seseorang } & \text { percaya } \\
\text { bahwasanya } & \\
\text { penggunaan } & \text { sistem } \\
\text { tertentu, } & \text { mampu } \\
\text { mengurangi } & \text { usaha } \\
\text { seseorang } & \text { dalam } \\
\text { mengerjakan } & \text { sesuatu. } \\
(\text { Davis, 1998) } & \\
\end{array}$ & \begin{tabular}{|ll} 
a. & $\begin{array}{l}\text { Teknologi } \\
\text { informasi } \\
\text { mudah }\end{array}$ \\
& dimengerti \\
b. & Sistem \\
& teknologi \\
& informasi \\
& mudah \\
& digunakan. \\
c. & Keyakinan \\
& akan \\
& kemanfaatan \\
(Davis, 1998)
\end{tabular} & Like \\
\hline
\end{tabular}

Analisis regresi sederhana digunakan untuk mengetahui pengaruh hubungan antar satu variabel independent (bebas) dengan variabel dependennya (terikat)

\section{HASIL DAN PEMBAHASAN}

Karakteristik demografi responden dalam penelitian ini merupakan profil dari 60 partisipan. Karakteristik responden ini meliputi nama, jenis kelamin, rentang usia, jenis usaha dan alamat. Demografi responden dapat dilihat pada tabel 4.1 berikut ini :

Tabel 4.1

Data Deskripsi Responden

\begin{tabular}{|c|l|c|c|}
\hline No & \multicolumn{1}{|c|}{ Kriteria } & Jumlah & Presentase \\
\hline 1 & Jenis kelamin & & \\
\hline & Laki-laki & 32 & $53 \%$ \\
\hline & Perempuan & 28 & $47 \%$ \\
\hline & Total & 60 & $100 \%$ \\
\hline 2 & Rentang Usia & & \\
\hline & Dibawah 15 Tahun & 1 & $1,7 \%$ \\
\hline & $16-64$ Tahun & 59 & $98,3 \%$ \\
\hline & Lebih dari 64 Tahun & 0 & $0 \%$ \\
\hline & Total & 60 & $100 \%$ \\
\hline 3 & Pendidikan Terakhir & & \\
\hline & SD & 3 & $5 \%$ \\
\hline & SMP & 5 & $8,3 \%$ \\
\hline & SMA & 20 & $33,3 \%$ \\
\hline
\end{tabular}




\begin{tabular}{|l|l|c|c|}
\hline & Diploma III & 12 & $20 \%$ \\
\hline & Sarjana (S1) & 20 & $33,3 \%$ \\
\hline & Master (S2) & 0 & $0 \%$ \\
\hline & Total & 60 & $100 \%$ \\
\hline
\end{tabular}

Sumber: data penulis, diolah 2019

Berdasarkan tabel 4.1 menunjukan bahwa dari 60 responden $53 \%$ responden berjenis kelamin laki-laki, sedangkan $47 \%$ berjenis kelamin perempuan.

Rentang usia menunjukan bahwa dari 60 responden $1,7 \%$ responden memiliki rentang usia kurang dari 15 Tahun, sedangkan 98,3\% responden memiliki rentang usia 16-64 Tahun. Hal ini menunjukkan bahwa responden dominan adalah 16-64 tahun.

Pendidikan terakhir menunjukan bahwa dari 60 responden 5\% responden memiliki pendidikan terakhir Sekolah Dasar (SD), 8,3\% responden memiliki pendidikan terakhir Sekolah Menengah Pertama (SMP), 33,3\% responden memiliki pendidikan terakhir Sekolah Menengah Atas (SMA), 20\% responden memiliki pendidikan terakhir Diploma III (D3) , 33,3\% responden memiliki pendidikan terakhir Sarjana (S1), dan yang terakhir tidak ada responden yang memiliki pendidikan terakhir Master (S2).

\section{Hasil Pengujian hipotesis}

Setelah melalui serangkaian pengujian, semua variabel dalam penelitian ini memenuhi hasil uji validitas dan reliabilitas. Berikut ini merupakan hasil untuk regresi sederhana untuk membuktikan adanya pengaruh atau tidak adanya pengaruh dari variabel persepsi kemudahan penggunaan fintech (X1) dan pembiayaan UMKM (Y).

Tabel 4.2. Analisis Linier Sederhana

\begin{tabular}{|c|c|c|c|c|c|}
\hline \multirow[b]{2}{*}{ Model } & \multicolumn{2}{|c|}{$\begin{array}{l}\text { Unstandardiz } \\
\text { ed } \\
\text { Coefficients }\end{array}$} & $\begin{array}{l}\text { Stand } \\
\text { ardize } \\
d \\
\text { Coeffi } \\
\text { cients }\end{array}$ & \multirow[b]{2}{*}{$\mathrm{t}$} & \multirow[b]{2}{*}{ Sig. } \\
\hline & B & Error & Beta & & \\
\hline $\begin{array}{l}1 \text { (Const } \\
\text { ant) }\end{array}$ & 1.518 & 1.208 & & $\begin{array}{r}1.2 \\
56\end{array}$ & $\begin{array}{r}.21 \\
4\end{array}$ \\
\hline $\begin{array}{l}\text { Fintec } \\
\mathrm{h} \\
\text { Adjust } \\
\text { ed } \mathrm{R}^{2}\end{array}$ & .513 & .041 & .854 & $\begin{array}{r}12 . \\
486\end{array}$ & $\begin{array}{r}.00 \\
0 \\
.72 \\
9\end{array}$ \\
\hline
\end{tabular}

Sumber : data diolah,2019.

Berdasarkan dari table 4.2 hasil analisis regresi sederhana menghasilkan koefisien untuk variabel bebas adalah $\mathrm{X} 1$ $=0.513$, dengan konstanta 1.518 Maka dari itu dapat dihasilkan persamaan regresi dalam penelitian ini adalah sebagai berikut: $\mathbf{Y}=\mathbf{1 . 5 1 8}+\mathbf{0 . 5 1 3} \mathrm{X}$

Berdasarkan tabel 4.2 menunjukan bahwa nilai Adjusted $R$ Square adalah sebesar 0,729 yang menandakan bahwa variabel independen hanya $72,9 \%$ mempengaruhi variabel dependen, sedangkan sisanya yaitu sebesar $27,1 \%$ pengaruh dari faktor lain diluar model regresi. Standar Error dalam penelitian ini sebesar 1,208. Hal tersebut menunjukkan bahwa nilai dari kesalahan pengganggu atau nilai-nilai dari variabel lain yang tidak dimasukan dalam model persamaan regresi adalah sebesar 1,208.

\section{Persepsi Kemudahan Penggunaan Fintech Terhadap Pembiayaan UMKM}

Para pelaku Usaha Mikro Kecil dan Menengah (UMKM) memiliki harapan untuk selalu meningkatkan usahanya. Dalam upaya tersebut UMKM membutuhkaan pembiayaan yang cukup untuk menompang usahanya. Dengan adanya Fintech membuat UMKM yang unbankable menjadi terakses. Pada ujungnya, fintech ini bisa membuat kapasitas usaha mengalami peningkatan (Henley, 2017). UMKM harus mampu bersaing. 
Berdasarkan total jawaban kuesioner untuk variabel $X$ (Fintech) dari 60 responden menyatakan bahwa terdapat pengaruh Fintech terhadap peningkatkan pembiayaan UMKM. Pada penelitian ini sejalan dengan teori Financial Stability Board (FSB) ) inovasi yang berbentuk Financial Technology (Fintech) dalam perkembangan UMKM memberikan manfaat yaitu : (1) dengan adanya Fintech dalam memberikan layanan pembayaran yang lebih efisien membuat semakin besar efisiensi pemain baru dalam menggunakan layanan keuangan yang berpotensi memberikan keuntungan (2) Memberikan pembiayaan dalam bentuk kredit kepada masyarakat yang memiliki usaha sehingga meningkatkan sumber permodalan dalam pengembangan usaha (3) penggunaan Fintech semakin meningkat sehingga diperlukan mengelola risiko dengan tepat untuk meminimalisir risiko operasional dan keamanan

Hasilnya dapat dilihat pada uji statistik $t$ yang menunjukan taraf signifikansi lebih kecil dari 0,05 yaitu 0,00 yang berarti $\mathrm{H}_{0}$ ditolak dan $\mathrm{H}_{1}$ diterima. Jadi Fintech berpengaruh positif terhadap pembiayaan UMKM. Hal tersebut bisa terjadi karena adanya respon positif dari para pelaku UMKM dan memberikan informasi yang jelas mengenai pinjaman yang ada.

Menurut Suyanto (2019) dalam menggunakan suatu sistem maka ada tingkat keyakinan yang menjadi salah satu bentuk dari persepsi kemudahan penggunaan, ketika seseorang menggunakan sistem maka tidak akan memerlukan usaha yang lebih, untuk menghilangkan adanya penolakan dari seseorang dalam menggunakan sistem maka sistem yang digunakan harus mudah dipakai oleh seseorang tanpa memerlukan usaha yang membuat menjadi memberatkan. Berdasarkan hal tersebut maka penelitian ini sesuai dengan penelitian sebelumnya karena dengan adanya kemudahan yang diberikan oleh fintech maka akan meningkatkan pembiayaan UMKM.

\section{KESIMPULAN}

Hasil penelitian menunjukkan bahwa variabel persepsi kemudahan menggunakan fintech berpengaruh positif terhadap pembiayaan UMKM. Hal tersebut menunjukkan bahwa semakin mudah penggunaan fintech akan semakin memudahkan UMKM dalam mendapatkan pembiayaan. Sehingga pembiayaan UMKM akan meningkat seiring dengan peningkatan kemudahan penggunaan fintech.

Adapun saran yang peneliti ajukan terkait dengan hasil penelitian ini adalah sebagai berikut : bagi pelaku UMKM, dalam mendapatkan sumber pembiayaan harus ada penilaian yang selektif terhadap fintech yang memberikan pembiayaan, agar tidak melakukan pinjaman terhadap fintech yang tidak terdaftar di Otoritas Jasa Keuangan (OJK). Dengan adanya penilaian yang selektif maka diharapkan akan memberi kemudahan dalam mendapatkan pembiayaan dengan melakukan pinjaman dengan proses yang cepat dan aman. Bagi penelitian selanjutnya, penelitian ini diharapkan mampu dikembangkan lagi dengan memberi variabel lain, dan menambah jumlah responden.

\section{REFERENCES}

Abor, J., dan P. Quartey. 2010. Issues in SME development in Ghana and South Africa. International Research Journal of Finance and Economics. 39 (6):219-227.

Aliyah, Lia Muhibatul dan Nurdin. 2019. Pengaruh Layanan Keuangan Berbasis Teknologi (Fintech) 
terhadap Literasi Keuangan Masyarakat Dago Atas, Bandung. Bandung. 5 (1): 650

Arifah, Nur. 2018. Implementasi Financial Technology Dalam Pengembangan Umkm Di Indonesia. Essay Booklet; The Tranformative Power of Fintech. Hal 21-29

Davis, Fred .D. 1989. Perceived Usefulness, Perceived Ease of Use, and User Acceptance of Information Technology. Management Information Systems Research Center. 13 (3):319-320

Davis, Fred .D., Richard P. Bagozzi and Paul R. Warshaw. 1989. User Acceptance Of Computer Technology: A Comparison Of Two Theoretical Models. Management Information Systems Research Center. 35 (8):982-986

Farn,Cheng-Kiang., Yi-Wen Fan, and Chun-Der Chen. 2006. Predicting Electronic Toll Collection Service Adoption: An Integration of the Technology Acceptance Model and the Theory of Planned Behavior. Department of Information Management. Hal 146

Financial Stability Board. 2019. FinTech and market structure in financial services: Market developments and potential financial stability implications. Hal 8-14

Galloway, Ian. 2009. Peer-to-Peer Lending and Community Development Finance. Community Investments. 21 (3):18-19

Ghozali, Imam. 2005. Aplikasi Analisis Multivariate dengan SPSS. Semarang: Badan Penerbit Universitas Diponegoro

Ghozali, Imam. 2013. Aplikasi Analisis Multivariate dengan Program SPSS. Edisi Ketujuh. Semarang :
Badan Penerbit Universitas Diponegoro

Harlan, Dwimastia. 2015. Pengaruh Kemudahan Penggunaan, Kepercayaan

Dan Risiko Persepsian Terhadap Minat Bertransaksi Menggunakan E-Banking Pada Umkm Di Kota Yogyakarta. Yogyakarta. 39-40

Murdwiyanto, Embun Fathia .2018. Faktor - Faktor Yang Memengaruhi Keputusan Umkm Dalam Mengambil Pinjaman Melalui PeerTo-Peer (P2p) Lending. Skripsi Institut Pertanian Bogor. Hal 11

Muzdalifa, Irma., Inayah Aulia Rahma, Bella Gita Novalia. 2018. Peran Fintech Dalam Meningkatkan Keuangan Inklusif Pada Umkm Di Indonesia (Pendekatan Keuangan Syariah). Jurnal Masharif alSyariah: Jurnal Ekonomi dan Perbankan Syariah. 3 (1):7

Naufal, Hanif Alif. 2018. Teknologi Finansial : Dari Keuangan Inklusif Menuju Pembangunan Inklusif melalui Skema Peer to Peer (P2P) Lending bagi Usaha Mikro, Kecil, dan Menegah (UMKM). Essay Booklet; The Tranformative Power of Fintech. Hal 54-55

Nuraini, Fitri. , Rieska Maharani, dan Andrianto. 2016. Strategi Peningkatan Daya Saing Umkm Dan Koperasi Dalam Menghadapi Aec (Asean Economic Community) : Suatu Telaah Kepustakaan. Prosiding Seminar Nasional Ekonomi dan Bisnis. Hal 495

Raise, Ahmad., Rifat, Ara., dan Dr. Altaf. 2013. Customer Attitude and Factors Influencing Users Acceptance of Ebanking in J\&K. 
International Journal of Business and Management Invention. Vol 2

Riadi, Muchlisin. 2014. Pengertian, Unsur, Tujuan dan Jenis Pembiayaan. https://www.kajianpustaka.com/20 14/02/pengertian-unsur-tujuanjenis-pembiayaan.html. Diakses Tanggal 27 Juli 2019

Rizkia, Nailah. 2018. Analisis

Perkembangan Usaha Mikro Kecil Dan Menengah (Umkm) Sebelum Dan Sesudah Memperoleh Pembiayaan Dari Bank Umum Syariah. Jakarta. 912

Santoso, Singgih. 2012. Panduan Lengkap SPSS Versi 20. Jakarta: PT Elex Media Komputindo

Sugiyono. 2010. Metode Penelitian Pendidikan Pendekatan Kuantitatif, kualitatif, dan R\&D. Bandung: Alfabeta

Sugiyono. 2013. Metode Penelitian Pendidikan Pendekatan Kuantitatif, Kualitatif, dan R\&D. Bandung: Alfabeta.

Sugiyono. 2016. Metode Penelitian Kuantitatif Kualitataif dan Kombinasi (Mixed Methods). Bandung: Alfabeta.

Suyanto, Taufan Adi Kurniawan. 2019. Faktor yang Mempengaruhi Tingkat Kepercayaan Penggunaan FinTech pada UMKM Dengan Menggunakan Technology Acceptance Model (TAM). Jurnal Akuntansi \& Manajemen Akmenika. 16 (1):185

Taylor, Shirley., and Peter A Todd. 1995. Understanding Information Technology Usage : A Test of Competing Models. . Management
Information Systems Research Center. 6 (2):144-145

UU No 20 Tahun 2008 tentang Usaha Mikro, Kecil, dan Menengah (UMKM)

Wibowo, Arif. 2006. Kajian tentang Perilaku Pengguna Sistem Informasi dengan Pendekatan Technology Acceptance Model (TAM). Jakarta : Universitas Budi Luhur

Wibowo, Budi. 2016. Analisa Regulasi Fintech Dalam Membangun Perekonomian Di Indonesia. Universitas Mercu Buana Jakarta. Hal 8

World Economic Forum. 2015. The Future of FinTech A Paradigm Shift in Small Business Finance.

Web

https://www.bi.go.id/id/edukasi-

perlindungan-

konsumen/edukasi/produk-dan-

jasa-

sp/fintech/Pages/default.aspx.

Diakses Tanggal 27 Juli 2019

https://www.bi.go.id/id/sistem-

pembayaran/fintech/Contents/defa

ult.aspx. Diakses Tanggal 27 Juli 2019

https://www.cnnindonesia.com/ekonomi/2

0180212145915-532-

275629/persyaratan-permodalanumkm-dinilai-berbelit-belit. Diakses

Tanggal 30 Juli 2019

https://www.jpnn.com/news/fintech-jadisolusi-pengembangan-umkm.

Diakses Tanggal 6 Agustus 2019

https://kbbi.kemdikbud.go.id/entri/modal

Diakses Tanggal 30 Juli 2019

http://www.depkop.go.id/data-umkm.

Diakses Tanggal 30 Juli 2019 